\title{
Association of Sociodemographic, Obstetric, and Attitudinal Factors with Prenatal Ultrasound in Mashhad, Iran
}

\author{
Lida Jarahi ${ }^{1}$ Rahil Mahmoudi ${ }^{2}$ Mohsen Vazifedar Yazd ${ }^{3}$ Hamidreza Ghodsi ${ }^{3}$ Mohammad Ramezani ${ }^{3}$ \\ Alireza Omranzadeh ${ }^{3}$ \\ ${ }^{1}$ Department of Community Medicine, Faculty of Medicine, Mashhad \\ University of Medical Sciences, Mashhad, Iran \\ ${ }^{2}$ Department of Community Medicine, Faculty of Medicine, Sabzevar \\ University of Medical Sciences, Sabzevar, Iran \\ ${ }^{3}$ Faculty of Medicine, Mashhad University of Medical Sciences, \\ Mashhad, Iran \\ J Child Sci 2021;11:e222-e226.

\begin{abstract}
Address for correspondence Alireza Omranzadeh, Faculty of medicine, Mashhad University of Medical Sciences, Azadi Sq., Mashhad, Iran (e-mail: Omranzadeha921@mums.ac.ir).
\end{abstract}

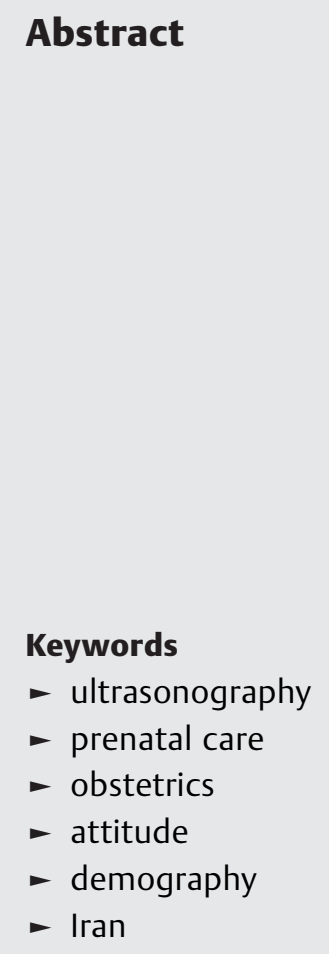

Many antenatal sonographies are out of indication and may be asked due to mothers' requests or other factors. However, these features are not fully understood. This study aimed to assess the association of sociodemographic, obstetric, and attitudinal factors that may affect the number of ultrasound scans. In a cross-sectional study in six hospitals affiliated with Mashhad University of Medical Sciences, 360 mothers who had a delivery or were expected to be near childbirth were enrolled in the study. The mean number of sonographies was compared between different study variables by using Mann-Whitney, Kruskal-Wallis, and Pearson's Chi-squared tests. Moreover, the Spearman Rho test was used to assess the correlation between different variables and the number of sonographies. Totally, 300 cases remained in the study. The mean age of the mothers was $25.95 \pm 4.77$ years, and the average number of ultrasonographies was $3.50 \pm 1.35$. In case of sociodemographic features, the level of education $(r=0.23$; $p<0.001)$ and several recent miscarriages $(r=0.140 ; p=0.01)$ were correlated with number of sonographies. However, there was no association between maternal age and marriage age with several sonographies $(p>0.05)$. Furthermore, mothers with higher family income $(p=0.010)$, those with medical insurance $(p=0.010)$, those who had male fetuses $(p=0.020)$, those who were clerk or student $(p=0.003)$, and those who were not aware of the sonography risks $(p=0.020)$ had more requests for sonography. It seems that financial factors and awareness of sonography risks play an essential role in sonography requests by mothers.

\section{Introduction}

Ultrasound examinations are usually requested with medical indications, such as prenatal screening. Mothers may undergo sonography to assess prenatal complications with

DOI https://doi.org/ 10.1055/s-0041-1733872. ISSN 2474-5871. valid reasons or evaluate fetal development due to adverse outcomes of some drugs or interventions. However, the mothers may request to have sonography without indication or out of routine screenings. ${ }^{1-3}$ Also, maternal

\section{(c) 2021. The Author(s).}

This is an open access article published by Thieme under the terms of the Creative Commons Attribution License, permitting unrestricted use, distribution, and reproduction so long as the original work is properly cited. (https://creativecommons.org/licenses/by/4.0/)

Georg Thieme Verlag KG, Rüdigerstraße 14, 70469 Stuttgart, Germany 
perspective should be manipulated and improved to manage health expenditures effectively. ${ }^{4-6}$ Furthermore, sociodemographic characteristics, obstetric history, and mothers' attitude can affect mothers' motivation toward ultrasound scans. ${ }^{7,8}$ Most of the ultrasound assessments are not according to the medical indications; examples are watching the baby and gender determination. This implies the necessity of research on pregnant women's attitudes toward ultrasound examinations. ${ }^{9,10}$

A previous study showed that several sociodemographic, obstetrics, and attitudinal factors affect mothers' requests for sonographies. ${ }^{7}$ Moreover, Garcia et al mentioned that besides mother and their partners, all staff should be well informed about ultrasound scans and their indications during pregnancy. ${ }^{11}$ Nevertheless, other studies have demonstrated that nonmedical reasons such as reassurance of normal fetal development, gender determination, and watching the baby on screen constitute the majority of ultrasound examinations. ${ }^{7,12,13}$ For example, in a crosssectional study, authors found that $23.2 \%$ of pregnant women in the United Kingdom had four or more ultrasound exams during their antenatal care in 1995. Interestingly, this figure had almost doubled by the year 2014. Moreover, ultrasounds with medical indications, such as dating and anomaly scans, also had increased from 31.1 and $68.7 \%$ to 95.1 and $99.1 \%$ in the span of 19 years, respectively. ${ }^{12}$ This means that irrespective of the scan reason, pregnant women in the United Kingdom are becoming more inclined to have more ultrasound exams during their antenatal care. However, as a health care provider perspective, scans with nonmedical indications are not cost effective and are a financial burden on the health care system.

Although most of the related studies on this matter have been conducted in other parts of the world, there is little amount of evidence regarding this issue in Iran. As mother's attitude toward perinatal sonography may be affected by several social, economic, and cultural factors; therefore, this study aimed to investigate sociodemographic, obstetric, and attitudinal factors that might affect preferences for prenatal ultrasound scan by assessing the number of requests and mothers' motivation for the prenatal ultrasound assessment in Mashhad, Iran.

\section{Materials and Methods}

\section{Study Population and Sample Size}

We conducted a cross-sectional study in six hospitals of Mashhad of Medical Sciences from March to June 2018. The study's sample size was calculated to be 360 volunteers, based on the Enakpene's study, using Cochrane method..$^{14} \mathrm{~A}$ simple nonrandom sampling method according to the number of admissions for delivery was used to collect data. Women who had delivered recently (postpartum period, 6 weeks after delivery) or were expecting to have an upcoming delivery (been in the third trimester) were included in the study and those who did not want to participate in the study or refused to continue were excluded. The mothers could have a normal vaginal delivery or a cesarean section.

\section{Data Collection}

A questionnaire was designed in a panel discussion of gynecologists and social medicine experts to collect data on the study. The questionnaires were filled out by the cooperation of participants and doctors as an interviewer. It had three parts, including sociodemographic data (mothers' age, mothers' age at the marriage time, mothers' level of education, mothers' career, family income, and having insurance), obstetric history (miscarriage age and number of miscarriage), and some information about prenatal ultrasound in current pregnancy (including the number of ultrasound examination, child sex and attitude of mothers toward possible ultrasound's risk factors).

\section{Ethics}

All the participants were provided with written informed consent and were allowed to discontinue the study. The patient's privacy and confidentiality of collected data were also considered. Moreover, the study protocol was approved by the Ethics Committee of Mashhad University of Medical sciences.

\section{Data Analysis}

Data were analyzed by using SPSS version 16. Mann-Whitney, Kruskal-Wallis, and Pearson's Chi-squared tests were used to compare the mean number of sonographies between different variables. Moreover, to assess the correlation between number of ultrasonographies and different study data, Spearman's Rho test was used. Statistical significance was considered $p<0.05$.

\section{Results}

\section{Study Participants}

Although it was estimated to have 360 mothers in our study, data of around 60 cases were missed, as they refused to continue the study and finally samples of 300 women were enrolled in the study. Participants had a mean age of $25.95 \pm 4.77$ years and an age range of 15 to 37 years. The average number of ultrasound scans was $3.50 \pm 1.35$, with a maximum of nine sonographies in three women $(1 \%)$. The data gathered from the women showed $6.6 \%$ of them had screening only in one trimester, $42.2 \%$ had a screening in two trimesters, and $51.1 \%$ had a screening in all three trimesters (-Table 1).

\section{The Motivation of Women for Prenatal Ultrasound}

As can be seen in - Fig. 1, the most crucial reason for requesting prenatal ultrasound is gender determination followed by fetus vitality and fetus age.

\section{Sociodemographic}

Our correlation test results showed that mothers with a higher education level requested more ultrasound scans $(r=0.23 ; p<0.001)$. Moreover, mothers whose jobs were clerks and students had more requests than others $(p=0.003)$. Furthermore, those mothers with a higher family income had more requests for sonographies $(p=0.010)$. 
Table 1 Age of the participants, the average number of ultrasound scans, and the distribution of scans through trimesters

\begin{tabular}{|c|c|c|}
\hline \multicolumn{2}{|l|}{ Variable } & $\begin{array}{l}\text { Total } \\
(n=300)\end{array}$ \\
\hline \multicolumn{2}{|l|}{ Age } & $25.95 \pm 4.77$ \\
\hline \multicolumn{2}{|c|}{ Ultrasound scans } & $3.50 \pm 1.35$ \\
\hline \multirow{3}{*}{$\begin{array}{l}\text { Scans during } \\
\text { trimesters }\end{array}$} & First trimester & $6.6 \%$ \\
\hline & Second trimester & $42.2 \%$ \\
\hline & Third trimester & $51.1 \%$ \\
\hline
\end{tabular}

Note: Data are presented as mean \pm standard deviation or $n(\%)$.

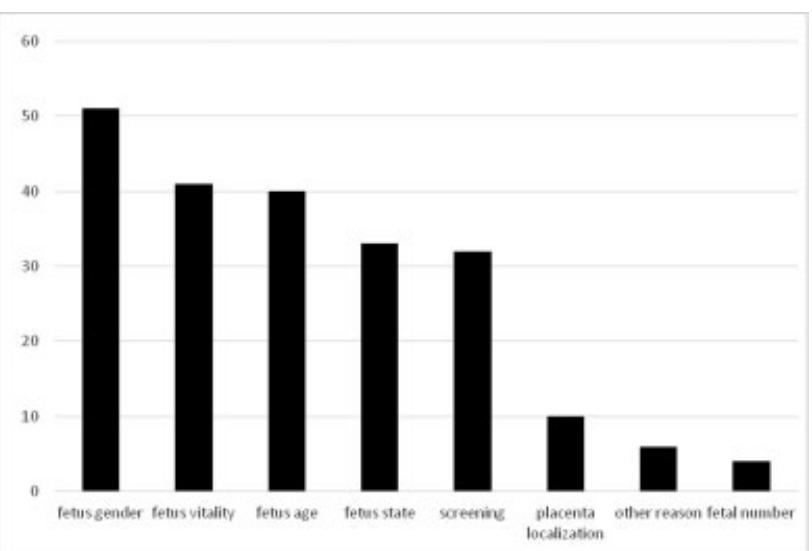

Fig. 1 Reasons of mothers to request prenatal ultrasonography by percent.

Mothers who had insurance also asked for more sonographies than those with no insurance $(p=0.010)$. At last, there was no significant association between ultrasound scan with maternal age and marriage age ( $p>0.05$; - Table 2 ).

\section{Obstetrics and Attitude}

Interestingly, mothers whose babies were boys had more requests for sonography than those with girls ( $p$-value $=0.020$ ). There was a significant association between ultrasound scans and the number of recent miscarriages $(r=0.140$; $p=0.01$ ). Moreover, the Kruskal-Wallis test showed mothers who believed that ultrasound scan is not harmful had more requests than others $(p=0.020 ;-$ Table 2$)$.

\section{Discussion}

This study proved that mothers with a high level of education had more requests for ultrasound scans, which may be due to the fact that their awareness about pregnancy complications are greater than mothers with low education levels. Furthermore, families with high socioeconomic status had better access to sonography and do not mind financial factors, as previous studies also supported this finding. ${ }^{7,15}$ Mothers who experienced miscarriage were more cautious about the fetus's vital signs and thus had a higher number of sonographies. Gudex et al concluded that experiencing re- cent miscarriages caused more demands for an antenatal ultrasound scan. ${ }^{7}$ Our analysis showed mothers' views about possible risk factors of ultrasonography influence their desire for this modality. However, some studies demonstrated that ultrasound examination and its repetition were safe in any ages. ${ }^{16-18}$ Surprisingly, we found that child sex and maternal career were associated with the number of ultrasound viewing, which was novel. May be, cultural factors may affect the families to be more cautious about male fetuses, as having a male child is preferred traditionally in rural areas of Mashhad due to religious reasons. Also, maternal career may affect the family income that may eliminate financial factors; however, this should be further investigated in future studies.

Notably, maternal age did not have any significant relation with number of requests, although one study observed that mothers with younger marriage age had more motivation for ultrasonography; thus, demographic variants such as average marriage age could differ between two populations. ${ }^{15}$ Moreover, our study pointed out that having insurance resulted in more ultrasound scans, supported by a previous study. Studies also pointed out that patients with private insurance requested more ultrasound scans. ${ }^{19}$ This should be considered by the authorities as requesting sonography without indication poses a further economic burden on the system. Finally, our study estimated distinct motivations for ultrasonography that gender determination was the most dominant, which contrasts with other studies; psychiatric factors such as women's attitudes and religion might differ in societies. ${ }^{20}$

Our studies, just like other studies, had some strong points and some shortcomings. On the one hand, doctors filled out questionnaires by interviewing participants as it was opposed to previous studies that participants filled questionnaires by themselves, which caused heavier bias. Contrary to most previous studies, we assessed the association of obstetric factors such as child sex and miscarriages. However, major limitation of this study was recall bias of the participants due to the study design. Another limitation of our study was that we did not assess other factors such as the level of partner's education, mother's characters (including the level of anxiety), and the prescriber's conflict of interest. In addition, the sample size of our study was no adequate to evaluate factors such as two recent miscarriages. Finally, the lack of randomization in choosing hospitals could result in sampling bias. With this regard, several future studies should be conducted to overcome these limitations.

\section{Conclusion}

In conclusion, this investigation showed that maternal motivation for ultrasound examination is influenced by some sociodemographic, obstetric, and attitudinal factors. Moreover, the findings of this research provide insights into the economic burden of nonindicated prenatal sonographies. As our study showed, mothers who had insurance requested more sonographies, which poses more pressure on the insurance system. However, the role of medical staff and doctors should be further investigated in this regard. Maybe, 
Table 2 Comparing the mean number of sonographies between different sociodemographic, obstetric, and attitudinal statuses and the results of correlation test

\begin{tabular}{|c|c|c|c|c|}
\hline \multicolumn{2}{|l|}{ Feature } & \multirow{2}{*}{$\begin{array}{l}\begin{array}{l}\text { Number of ultrasound scans } \\
\text { (mean } \pm \text { SD) }\end{array} \\
3.17 \pm 1.21\end{array}$} & \multirow{2}{*}{$\begin{array}{l}\begin{array}{l}n \\
(\%)\end{array} \\
42 \\
(14.0)\end{array}$} & \multirow{2}{*}{$\begin{array}{l}p \text {-Value } \\
0.64\end{array}$} \\
\hline \multirow[t]{4}{*}{ Maternal age $^{a}$} & $\leq 20$ & & & \\
\hline & $20-25$ & $3.58 \pm 1.13$ & $\begin{array}{l}97 \\
(32.3)\end{array}$ & \\
\hline & $25-30$ & $3.56 \pm 1.84$ & $\begin{array}{l}102 \\
(34.0)\end{array}$ & \\
\hline & $30 \leq$ & $3.19 \pm 2.02$ & $\begin{array}{l}59 \\
(19.6)\end{array}$ & \\
\hline \multirow[t]{4}{*}{ Level of education $^{a}$} & Illiterate or elementary & $2.97 \pm 2.04$ & $\begin{array}{l}58 \\
(19.3)\end{array}$ & \multirow[t]{4}{*}{$<0.001$} \\
\hline & Diploma & $3.48 \pm 2.09$ & $\begin{array}{l}153 \\
(51.0)\end{array}$ & \\
\hline & Associate $D^{b}$ & $3.33 \pm 2.22$ & $\begin{array}{l}24 \\
(8.0)\end{array}$ & \\
\hline & Bachelor's D & $3.80 \pm 1.98$ & $\begin{array}{l}65 \\
(21.7)\end{array}$ & \\
\hline \multirow[t]{5}{*}{ 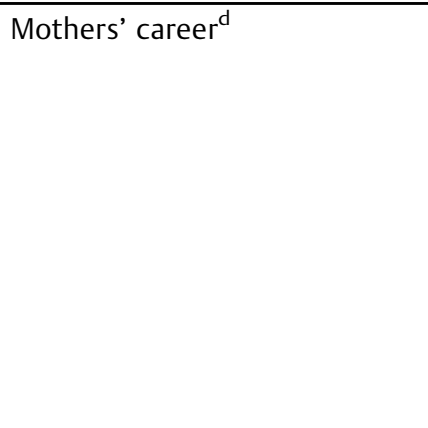 } & House wife & $3.40 \pm 1.68$ & $\begin{array}{l}268 \\
(89.3)\end{array}$ & \multirow[t]{5}{*}{0.0003} \\
\hline & Clerk & $3.73 \pm 1.58$ & $\begin{array}{l}2 \\
(0.7)\end{array}$ & \\
\hline & Worker and farmer & $2.00 \pm 1.45$ & $\begin{array}{l}4 \\
(1.3)\end{array}$ & \\
\hline & Student & $4.50 \pm 1.25$ & $\begin{array}{l}22 \\
(7.3)\end{array}$ & \\
\hline & Self-employee & $4.00 \pm 1.75$ & $\begin{array}{l}4 \\
(1.3)\end{array}$ & \\
\hline \multirow[t]{3}{*}{ Family income ${ }^{d}$} & Low & $3.30 \pm 1.64$ & $\begin{array}{l}105 \\
(35.0)\end{array}$ & \multirow[t]{3}{*}{0.01} \\
\hline & Moderate & $3.41 \pm 1.33$ & $\begin{array}{l}143 \\
(47.7)\end{array}$ & \\
\hline & High & $3.80 \pm 1.54$ & $\begin{array}{l}50 \\
(16.7)\end{array}$ & \\
\hline \multirow[t]{2}{*}{ Insurance $^{\mathrm{b}}$} & Yes & $3.47 \pm 1.25$ & $\begin{array}{l}273 \\
(91.0)\end{array}$ & \multirow[t]{2}{*}{0.01} \\
\hline & No & $3.11 \pm 1.34$ & $\begin{array}{l}27 \\
(9.0)\end{array}$ & \\
\hline \multirow[t]{3}{*}{ Marriage age $^{a}$} & \multirow[t]{2}{*}{$<20$} & \multirow[t]{2}{*}{$3.42 \pm 1.28$} & $122(40.7)$ & \multirow[t]{3}{*}{0.055} \\
\hline & & & $\begin{array}{l}86 \\
(28.7)\end{array}$ & \\
\hline & $20 \leq$ & $3.48 \pm 1.05$ & $\begin{array}{l}92 \\
(30.7)\end{array}$ & \\
\hline \multirow[t]{3}{*}{ Number of recent miscarriage ${ }^{c}$} & 0 & $3.42 \pm 1.08$ & $\begin{array}{l}255 \\
(85.0)\end{array}$ & \multirow[t]{3}{*}{0.55} \\
\hline & 1 & $3.92 \pm 1.09$ & $\begin{array}{l}24 \\
(8.0)\end{array}$ & \\
\hline & 2 & $3.14 \pm 1.14$ & $\begin{array}{l}21 \\
(7.0)\end{array}$ & \\
\hline
\end{tabular}


Table 2 (Continued)

\begin{tabular}{|c|c|c|c|c|}
\hline \multicolumn{2}{|l|}{ Feature } & \multirow{2}{*}{$\begin{array}{l}\begin{array}{l}\text { Number of ultrasound scans } \\
\text { (mean } \pm \text { SD) }\end{array} \\
3.60 \pm 1.65\end{array}$} & \multirow{2}{*}{$\begin{array}{l}\begin{array}{l}n \\
(\%)\end{array} \\
153 \\
(51.0)\end{array}$} & p-Value \\
\hline Child sex ${ }^{\mathrm{b}}$ & Male & & & \multirow[t]{2}{*}{0.02} \\
\hline & Female & $3.20 \pm 1.24$ & $\begin{array}{l}55 \\
(18.3)\end{array}$ & \\
\hline \multirow[t]{2}{*}{ Attitude toward sonography risk ${ }^{c}$} & It has no risk & $3.67 \pm 1.27$ & $\begin{array}{l}84 \\
(28.0)\end{array}$ & \multirow[t]{2}{*}{0.02} \\
\hline & Have no idea about the risk & $3.35 \pm 1.40$ & $\begin{array}{l}210 \\
(70.0)\end{array}$ & \\
\hline
\end{tabular}

Abbreviation: SD, standard deviation.

aLevel of education, maternal age, marriage age and level of education were analyzed with Spearman Rho.

${ }^{b}$ Child sex and having insurance were analyzed with Mann-Whitney.

'A number of recent miscarriages and mother's attitude about ultrasound risks were analyzed with Kruskal-Wallis test.

${ }^{\mathrm{d}}$ Maternal career and family income was analyzed with Pearson's Chi-square test.

restriction in nonindicated sonographies further helps system improvement and even fetus health.

\section{Funding}

None.

\section{Conflict of Interest}

None declared.

\section{References}

1 Whitworth M, Bricker L, Mullan C. Ultrasound for fetal assessment in early pregnancy. Cochrane Database Syst Rev 2015;(07): CD007058

2 Bakst S, Romano-Zelekha O, Ostrovsky J, Shohat T. Determinants associated with making prenatal screening decisions in a national study. J Obstet Gynaecol 2019;39(01):41-48

3 Farahmand S, Abdolhoseini A, Aliniagerdroudbari E, Babaniamansour S, Baratloo A, Bagheri-Hariri S. Point-of-care ultrasound modalities in terms of diagnosing acute decompensated heart failure in emergency department; a diagnostic accuracy study. Internal Emerg Med 2020;15(03):491-499

4 van den Berg M, Timmermans DR, Ten Kate LP, van Vugt JM, van der Wal G. Are pregnant women making informed choices about prenatal screening? Genet Med 2005;7(05):332-338

5 Agbata AT, Ukaegbe CI, Lawani LO, Ekwedigwe KC, Ajah LO. Women's views on routine antenatal ultrasound scan in a low resource nigerian setting. J Clin Diagn Res 2018;12(06):

6 Ghodsi A, Bijari M, Alamdaran SA, et al. Chest computed tomography findings of COVID-19 in children younger than 1 year: a systematic review. World J Ped 2021:1-8

7 Gudex C, Nielsen BL, Madsen M. Why women want prenatal ultrasound in normal pregnancy. Ultrasound Obstet Gynecol 2006;27(02):145-150

8 Hitimana R, Lindholm L, Krantz G, Nzayirambaho M, PulkkiBrännström A-M. Systematic review of cost and cost-effectiveness of routine ultrasound during pregnancy. Accessed at: http://umu. diva-portal.org/smash/record.jsf?pid=diva2\% 3A1261325\&dswid $=64502018$
9 Ikeako L, Ezegwui H, Onwudiwe E, Enwereji J. Attitude of expectant mothers on the use of ultrasound in pregnancy in a tertiary institution in South East of Nigeria. Ann Med Health Sci Res 2014; 4(06):949-953

10 Buyukbayrak EE, Soysal S, Anik Ilhan G, Yavuzer O. What do expectant parents know about antenatal ultrasound screening? J Matern Fetal Neonatal Med 2020;33(11):1811-1817

11 Garcia J, Bricker L, Henderson J, et al. Women's views of pregnancy ultrasound: a systematic review. Birth 2002;29(04):225-250

12 Henderson J, Redshaw M. Change over time in women's views and experiences of maternity care in England, 1995-2014: a comparison using survey data. Midwifery 2017;44:35-40

13 Simó S, Zúñiga L, Izquierdo MT, Rodrigo MF. Effects of ultrasound on anxiety and psychosocial adaptation to pregnancy. Arch Women Ment Health 2019;22(04):511-518

14 Enakpene CA, Morhason-Bello IO, Marinho AO, et al. Clients reasons for prenatal ultrasonography in Ibadan, South West of Nigeria. BMC Womens Health 2009;9(01):12

15 Huang K, Tao F, Raven J, Liu L, Wu X, Tang S. Utilization of antenatal ultrasound scan and implications for caesarean section: a crosssectional study in rural Eastern China. BMC Health Serv Res 2012; 12(01):93

16 Torloni MR, Vedmedovska N, Merialdi M, et al; ISUOG-WHO Fetal Growth Study Group. Safety of ultrasonography in pregnancy: WHO systematic review of the literature and meta-analysis. Ultrasound Obstet Gynecol 2009;33(05):599-608

17 Newnham JP, Doherty DA, Kendall GE, Zubrick SR, Landau LL, Stanley FJ. Effects of repeated prenatal ultrasound examinations on childhood outcome up to 8 years of age: follow-up of a randomised controlled trial. Lancet 2004;364(9450):2038-2044

18 Drukker L, Droste R, Chatelain P, Noble JA, Papageorghiou AT. Safety indices of ultrasound: adherence to recommendations and awareness during routine obstetric ultrasound scanning. Ultraschall Med 2020;41(02):138-145

19 Davidson C, Mastrobattista J, Ramirez M, Monga M. Utilization of obstetrical ultrasound in a referral population. J Matern Fetal Neonatal Med 2004;191(06):S180

20 Ugwu A, Osungbade E, Erondu F. Maternal perspectives of prenatal sonogram in a north-eastern population in Nigeria. Libyan J Med 2009;4(04):140-142 